\title{
Diseño y aplicación de encuesta para evaluar el trabajo colaborativo en primer año de Enfermería
}

\section{Design and application of a survey to evaluate collaborative work in the first year of nursing.}

\author{
DOI: $10.46932 / \mathrm{sfjdv2n2-019}$
}

Received in: january 1st, 2020

Accepted in: March 30th, 2020

\section{Fidelina González}

Biólogo marino, Dr. en Ciencias Ambientales. Diplomada en Educación Superior, Diplomada en Competencias Genéricas.

Correspondencia: fgonzale@udec.cl

\author{
Katia Sáez \\ Ingeniero Matemático. Dr. en Estadística. Diplomada en Educación Superior, Diplomada en \\ Competencias Genéricas. \\ Correspondencia:ksaez@udec.cl
}

\begin{abstract}
Elizabeth Bastias
Enfermera. Dr. en Enfermería. Diplomada en Competencias Genéricas.

Correspondencia: elibastias@udec.cl
\end{abstract}

\section{Rocío Catalán}

Psicólogo. Postgrado Diplomado en Responsabilidad Social. Facultad de Ingeniería, Correspondencia: rociocatalan@udec.cl

\section{RESUMEN}

Con el fin de evaluar el trabajo colaborativo en la asignatura de Biología Celular para Enfermería se diseñó, validó y aplicó una encuesta a los estudiantes de primer año, para indagar respecto de su opinión sobre las actividades desarrolladas en la asignatura relacionadas a trabajo individual y trabajo colaborativo.

Objetivo: Evaluar y fomentar el aprendizaje colaborativo con el fin de lograr aprendizajes significativos en la asignatura de Biología Celular.

Método: Se diseñó una encuesta con ítems en la plataforma Google Drive, que incluye: respuesta múltiple, con escala de Likert y respuesta abierta. Los aspectos considerados fueron nivel de identificación de las competencias genéricas, competencias para responder en equipo, nivel de reconocimiento del trabajo colaborativo respecto al aprendizaje logrado, apreciación de los componentes básicos del aprendizaje cooperativo de acuerdo a Johnson \& Johnson, 2009.

Resultados y discusión.

De acuerdo al análisis de los ítems de la encuesta, se aprecia que los estudiantes valoran el trabajo colaborativo en su proceso de aprendizaje y práctica de habilidades blandas o competencias genéricas, en los que la Universidad de Concepción se encuentra comprometida.

Palabras Claves: Competencias genéricas, trabajo colaborativo, aprendizaje significativo. 


\begin{abstract}
In order to evaluate collaborative work in the subject of Cell Biology for Nursing, a survey was designed, validated and applied to first year students to inquire about their opinion on the activities developed in the subject related to individual and collaborative work.

Objective: To evaluate and promote collaborative learning in order to achieve significant learning in the subject of Cell Biology.

Method: A survey was designed with items in the Google Drive platform, including: multiple response, Likert scale and open response. The aspects considered were level of identification of generic competencies, competencies to respond in a team, level of recognition of collaborative work with respect to the learning achieved, appreciation of the basic components of cooperative learning according to Johnson \& Johnson, 2009.

Results and discussion.

According to the analysis of the survey items, it can be seen that students value collaborative work in their learning process and practice of soft skills or generic competencies, to which the Universidad de Concepción is committed.
\end{abstract}

Key words: Generic competencies, collaborative work, meaningful learning.

\title{
1 INTRODUCCIÓN:
}

Hemos realizado una investigación sobre la percepción de los estudiantes del trabajo en equipos en las actividades de la asignatura Biología Celular, en el primer año de estudiantes de Enfermería, en virtud de la implementación del Modelo Educativo de la Universidad de Concepción. Las competencias genéricas consideradas en este modelo son pensamiento crítico, comunicación oral y escrita, emprendimiento y trabajo en equipos y responsabilidad social que se implementaron a nivel conceptual en el contexto de los contenidos de la asignatura.

Una de las características del trabajo en equipo es ser realizado por varios individuos donde cada uno aporta al cumplimiento de un objetivo común. Además, se debe favorecer un proceso en el cual todos los integrantes desarrollen un sentido de pertenencia al grupo, asimismo, deben ser conscientes de la interdependencia de los miembros del grupo. En este sentido, las actividades grupales desarrolladas en la asignatura se transforman en un espacio donde los estudiantes no sólo puedan profundizar los contenidos propios de la asignatura, sino también puedan integrar los conceptos sobre las competencias genéricas y a la vez poner en práctica lo que han aprendido (Jara 2021).

\section{OBJETIVO}

Evaluar y fomentar el aprendizaje colaborativo con el fin de lograr aprendizajes significativos en la asignatura de Biología Celular. 


\section{MÉTODO}

Diseñamos una encuesta con ítems en la plataforma Google Drive, en un formulario electrónico, que incluye: respuesta múltiple (Preguntas P, considerando cinco niveles nunca, rara vez, algunas veces casi siempre y siempre), con escala de Likert (calificando de 1-7) (Preguntas E) y respuesta abierta indicando los aspectos favorables (máximo 3) y desfavorables (máximo 3) para el aprendizaje de las actividades o materiales disponibles en la asignatura. Los aspectos considerados fueron nivel de identificación de las competencias genéricas, competencias para responder en equipo, nivel de reconocimiento del trabajo colaborativo respecto al aprendizaje logrado, apreciación de los componentes básicos del aprendizaje cooperativo de acuerdo a Johnson y Johnson, 2009.

Un total de 198 estudiantes respondieron voluntaria y confidencialmente "online" durante el último mes de dos primeros semestres de 2015 y 2016. Para la validación se usó la promoción de 2015, aplicado a un total de 105 estudiantes. Los estudiantes tienen alrededor de 18 años, la mayor parte son recién egresados de la enseñanza media. Los datos fueron automáticamente vertidos a una planilla Excel desde donde fue calculado el estadístico de confiabilidad alfa de Cronbach general y por dimensión. Las respuestas abiertas fueron codificadas y clasificadas para ser comparadas con las respuestas entregadas por cada participante con la escala de Likert y verificar la coherencia de la información y validez de los contenidos. Se utilizó Análisis Factorial Exploratorio (AFE) usando componentes principales y rotación varimax, para verificar la congruencia y pertinencia de los ítems.

\section{RESULTADOS}

La confiabilidad y validez de la encuesta correspondiente a las preguntas P y E en Tabla 1. Las dimensiones resultantes del agrupamiento luego del Análisis Factorial Exploratorio (AFE) se muestran en la Tabla 2 y la confiabilidad de cada dimensión en la Tabla 3. La base de los datos obtenida integró 95 observaciones para ambos casos, obteniéndose un cuociente que se considera aceptable mayor a 5 (para preguntas $\mathrm{P}$ es 6,8 y para preguntas $\mathrm{E}$ es 5,6), siendo óptimo un cuociente de 10 (Hair, Anderson, Tatham y Black, 1999).

Tabla 1. Resumen del procesamiento de los casos de las preguntas $\mathrm{P}$ y E.

\begin{tabular}{|l|c|c|c|c|}
\hline & Preguntas P & \multicolumn{2}{c|}{ Preguntas E } \\
\hline & $\mathrm{N}$ & $\%$ & $\mathrm{~N}$ & $\%$ \\
\hline Casos Válidos & 90 & 94,7 & 94 & 98,9 \\
\hline Casos Excluidosa & 5 & 5,3 & 1 & 1,1 \\
\hline Total Casos & 95 & 100,0 & 95 & 100,0 \\
\hline $\begin{array}{l}\text { Estadísticos de } \\
\text { fiabilidad }\end{array}$ & \multicolumn{3}{|c|}{0,890} \\
\hline Alfa de Cronbach & \multicolumn{2}{|c|}{0,911} & & \\
\hline
\end{tabular}




\begin{tabular}{|l|c|c|}
\hline Total elementos & 14 & 17 \\
\hline a Eliminación por lista basada en todas las variables del procedimiento. \\
\hline
\end{tabular}

Tabla 2. Resumen de las dimensiones que agrupan los elementos resultantes del Análisis Factoral Exploratorio (AFE) de las preguntas P y E.

\begin{tabular}{|c|c|c|}
\hline Criterio & Nombre del criterio & Preguntas \\
\hline \multicolumn{3}{|c|}{$\begin{array}{l}\text { Preguntas }(\mathbf{P}) \text { con respuesta escala de Likert con criterios de nunca, rara vez, algunas veces, casi siempre y } \\
\text { siempre }\end{array}$} \\
\hline 1 & $\begin{array}{l}\text { Dimensión Cognitiva } \\
\text { de Competencias } \\
\text { Genéricas }\end{array}$ & $\begin{array}{l}\text { P6. Responder preguntas para preparar seminarios en equipo de trabajo me } \\
\text { permite visualizar mejor la responsabilidad social } \\
\text { He visualizado que logro integrar, gracias al trabajo en equipos los saberes } \\
\text { disciplinares y los de: } \\
\text { P7. pensamiento crítico } \\
\text { P8. comunicación oral y escrita } \\
\text { P9. emprendimiento } \\
\text { P10. responsabilidad social }\end{array}$ \\
\hline 2 & $\begin{array}{l}\text { Dimensión aplicación } \\
\text { de Competencias } \\
\text { Genéricas en el } \\
\text { Trabajo colaborativo }\end{array}$ & $\begin{array}{l}\text { El trabajo en equipos para la elaboración del folleto me permite aplicar los } \\
\text { conceptos de } \\
\text { P11. pensamiento crítico } \\
\text { P12. comunicación oral y escrita } \\
\text { P13. emprendimiento } \\
\text { P14. responsabilidad social }\end{array}$ \\
\hline 3 & $\begin{array}{l}\text { Dimensión ventajas } \\
\text { del trabajo } \\
\text { colaborativo en virtud } \\
\text { del aprendizaje }\end{array}$ & $\begin{array}{l}\text { Responder preguntas para preparar seminarios: } \\
\text { P2. favorece mi aprendizaje de contenidos del seminario } \\
\text { P3. me motiva a colaborar con mis compañeros y compañeras de grupo } \\
\text { P4. en grupo de trabajo me motiva a desarrollar el pensamiento crítico } \\
\text { P5. en equipo de trabajo me permite practicar y mejorar la comunicación } \\
\text { del tema de seminario }\end{array}$ \\
\hline \multicolumn{3}{|c|}{ Preguntas $(\mathbf{E})$ con calificación de 1 a 7.} \\
\hline 4 & $\begin{array}{l}\text { Dimensión } \\
\text { componentes } \\
\text { esenciales del trabajo } \\
\text { colaborativo }\end{array}$ & $\begin{array}{l}\text { E13. Interdependencia positiva } \\
\text { E14. Interacción cara a cara } \\
\text { E16. Desarrollo de habilidades sociales }\end{array}$ \\
\hline 5 & $\begin{array}{ll}\text { Dimensión estrategias } \\
\text { de } & \text { trabajo } \\
\text { colaborativo de la } \\
\text { asignatura }\end{array}$ & $\begin{array}{l}\text { E3. Folleto } \\
\text { E11. Preparación del folleto } \\
\text { E12, Preparación de seminarios }\end{array}$ \\
\hline 6 & $\begin{array}{l}\text { Dimensión estrategias } \\
\text { de trabajo de } \\
\text { laboratorio }\end{array}$ & $\begin{array}{l}\text { E4. Laboratorio } \\
\text { E9. Manual de Laboratorio }\end{array}$ \\
\hline 7 & Dimensión evaluativa & $\begin{array}{l}\text { E8. Evaluaciones Electrónicas } \\
\text { E10.Autoestudio } \\
\text { E15.Responsabilidad Personal } \\
\end{array}$ \\
\hline 8 & $\begin{array}{l}\text { Dimensión estrategias } \\
\text { pedagógicas I }\end{array}$ & $\begin{array}{l}\text { E1. Clase Expositiva } \\
\text { E7. TBL }\end{array}$ \\
\hline 9 & $\begin{array}{l}\text { Dimensión estrategias } \\
\text { pedagógicas Ii }\end{array}$ & $\begin{array}{l}\text { E4.Laboratorio } \\
\text { E5.Películas } \\
\text { E6.Cuestionario en Laboratorio } \\
\text { E9. Manual de Laboratorio }\end{array}$ \\
\hline
\end{tabular}


Tabla 3. Resumen de la confiabilidad de las dimensiones resultantes del análisis factorial exploratorio.

\begin{tabular}{|l|l|c|}
\hline Criterio & Nombre del criterio & Alfa de Cronbach \\
\hline 1 & Dimensión Cognitiva de Competencias Genéricas & 0,858 \\
\hline 2 & Dimensión aplicación de Competencias Genéricas en el Trabajo colaborativo & 0,817 \\
\hline 3 & Dimensión ventajas del trabajo colaborativo en virtud del aprendizaje & 0,794 \\
\hline 4 & Dimensión componentes esenciales del trabajo colaborativo & 0,766 \\
\hline 5 & Dimensión estrategias de trabajo colaborativo de la asignatura & 0,829 \\
\hline 6 & & 0,804 \\
\hline 7 & Dimensión estrategias de trabajo de laboratorio & 0,724 \\
\hline 8 & Dimensión evaluativa & 0,57 \\
\hline 9 & Dimensión estrategias pedagógicas I & 0,764 \\
\hline
\end{tabular}

Los estudiantes valoran el trabajo colaborativo desarrollado en la asignatura como lo evidencian las respuestas a la encuesta de ambas promociones de estudiantes consultadas, especialmente en la sección de respuesta abierta, sobre lo que considera favorable al aprendizaje. Los aspectos favorables para el aprendizaje son trabajo colaborativo (62\%), laboratorio (50\%), videos $(27 \%)$ y manual de laboratorio (21\%). Entre los aspectos desfavorables para su aprendizaje que presentan entre 20 y $40 \%$ de las opiniones de los estudiantes son clases magistrales (36\%), las presentaciones con power point (27\%), los videos (25\%), las características personales (21\%). Alrededor de $15 \%$ de las opiniones de los estudiantes considera el trabajo colaborativo (15\%) y asignatura recargada (14\%) son desfavorable al aprendizaje en la asignatura.

Un $88 \%$ de los estudiantes considera que el trabajo en equipos favorece la comunicación oral y escrita en la preparación de los temas de seminarios (P5) y de aplicación de conceptos de comunicación (P12) en la elaboración del folleto (Fig.1). Un porcentaje mayor al 70\% de los estudiantes considera que favorece el aprendizaje de los temas (P2) e integrar los contenidos disciplinares y de comunicación oral y escrita (P8), de pensamiento crítico (P4, P7, P11) y de responsabilidad social (P14, P10, P6), y de emprendimiento (P9, P13).También motiva a la colaboración entre pares (P3). Un porcentaje levemente menor al 70\% considera que responder preguntas de cuestionarios en grupo favorece mi aprendizaje de los contenidos disciplinares de la asignatura de Biología Celular (P1).

Alrededor del $90 \%$ de los estudiantes calificó como características personales importantes para su aprendizaje la responsabilidad personal (E15), interacción cara a cara (E14), reflexión sobre el trabajo en grupo (E17), interdependencia positiva (E13), desarrollo de habilidades sociales (E16) y autoestudio (E10) (Fig. 2). 
Entre las estrategias de presentación de los contenidos que los estudiantes consideraron importantes para su aprendizaje son: seminarios (E2), manual de laboratorio (E9), laboratorio (E4), preparación de seminarios (E11), folleto (E3) y preparación del folleto (E11).

Los resultados preliminares indican que el rendimiento académico está relacionado con la dimensión ventajas del trabajo colaborativo en virtud del aprendizaje y la estrategia de trabajo grupal Elaboración del Folleto, sobre la base de 186 casos se obtuvo un valor de $\mathrm{r}$ de Pearson de 0,17, con un valor $P$ de 0,0191 .

Sobre una base de 195 casos, la dimensión componentes esenciales del trabajo colaborativo está positivamente correlacionada con las dimensiones Cognitiva de Competencias Genéricas (valor de $\mathrm{r}$ de Pearson de 0,35 , con un valor $P$ de $<0,0001)$, aplicación de Competencias Genéricas en el Trabajo colaborativo (valor de $\mathrm{r}$ de Pearson de 0,51 , con un valor $P$ de $<0,0001$ ) y ventajas del trabajo colaborativo en virtud del aprendizaje (valor de $\mathrm{r}$ de Pearson de 0,38 , con un valor $P$ de $<0,0001$ ). Además la dimensión componentes esenciales del trabajo colaborativo está positivamente correlacionada con las dimensiones estrategias de trabajo colaborativo de la asignatura (valor de $\mathrm{r}$ de Pearson de 0,38 , con un valor $P$ de $<0,0001$ ), estrategias de trabajo de laboratorio valor de $\mathrm{r}$ de Pearson de 0,55, con un valor $P$ de $<0,0001$ ), evaluativa valor de $\mathrm{r}$ de Pearson de 0,48 , con un valor $P$ de $<0,0001)$ y estrategias pedagógicas I valor de r de Pearson de 0,48, con un valor $P$ de $<0,0001)$.

Figura 1. Respuesta de los estudiantes de las promociones 2015 y 2016 a preguntas P.

\section{Porcentaje respuesta a preguntas $\mathbf{P}$}

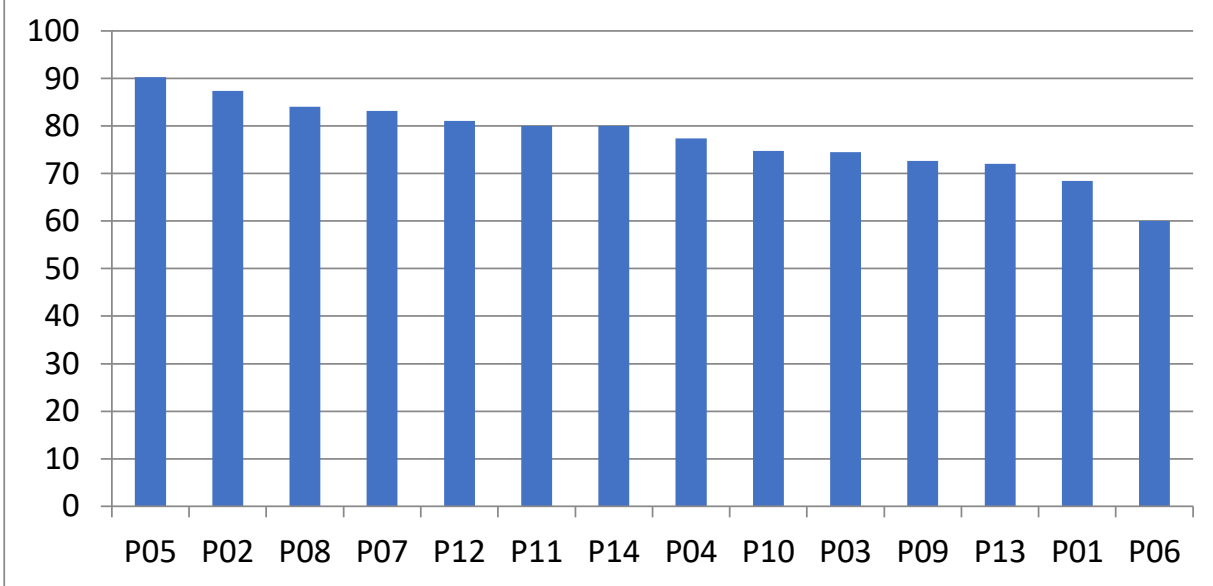


Figura 2. Respuesta de los estudiantes de las promociones 2015 y 2016 a preguntas E.

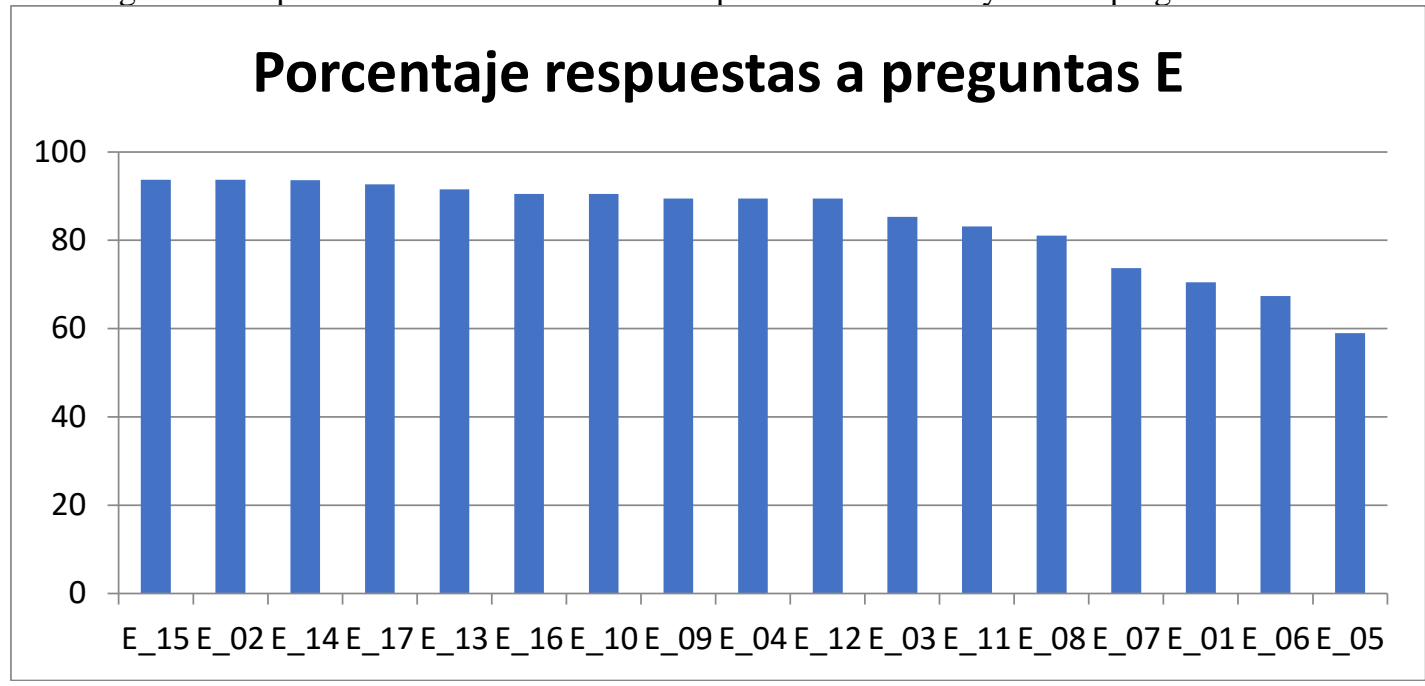

\section{CONCLUSIONES:}

Este es un trabajo que se encuentra en progreso. Las conclusiones preliminares son que la encuesta puede ser un instrumento confiable que puede ser utilizada para indagar sobre la percepción del trabajo colaborativo en la asignatura. Los estudiantes perciben de forma positiva el trabajo colaborativo en virtud de su aprendizaje tanto de los contenidos propios de la asignatura y el aprendizaje e integración de las competencias genéricas. Sobre esta base podemos hacer modificaciones para optimizar el rendimiento de los estudiantes en la asignatura potenciando el trabajo en equipos en la asignatura.

\section{REFERENCIAS}

Hair Jr, J. F., Anderson, R. E., Tatham, R. L., \& Black, W. C. (1999). Análisis Multivariante. 5ta Edicion Prentice Hall. Links, 469-488.

Jara, G. I. T. (2021). Experiencia: incorporación de aprendizaje servicio en asignaturas de la carrera de enfermería Universidad Santo Tomas. Santiago, Chile. 2017. South Florida Journal of Development, 2(1), 559-565.

Johnson, D. y Johnson, R. (1999). Aprender juntos y solos. Aprendizaje cooperativo, competitivo e individualista (trad. de M. Wald). Buenos Aires: Aique. [V.O.: Learning together and alone: cooperative, competitive and individualistic learning. Needham Heights: Allyn \& Bacon, 19136599]. 